\title{
Different Presents in the Making
}

Mike Anusas, University of Strathclyde and Rachel Harkness, University of Aberdeen

In press for forthcoming edited volume: Otto, T. and Smith, R. C. (2016) Designing Anthropological Futures, Bloomsbury.

\section{Positionings and possibilities}

This chapter seeks to challenge aspects of anthropology and design that curtail their potential to be significant agents of social, material and ecological change for the better. In doing so we also seek to open up the possibility for the anthropological imagination to play a greater role in the shaping of the world; we are critical of anthropology where the discipline tends not to build upon observations of the world and keeps itself at an arm's length from the practical formation of future environments and things. Addressing design, we critique practices that produce and proliferate material things largely ignorant of the extended dynamics of time, materials and ecology. Whilst we acknowledge that these versions of the disciplines are to some extent stereotypes and (therefore) do not reflect their full scope, we still make the case that there is need for a radical reformulation of how materials, time and ecology are considered in anthropologically-informed processes of design and making.

We develop our argument through the discussion of periods of participant observation that we carried out within two distinct situations of making. The first case is concerned with everyday working life in a product design studio, where activities of making are situated within a commercial consulting context. Here we examine how day-to-day experiences of time become contracted and relations with materials and ecology become narrowed. The second case focuses upon the practice of self-building, whereby people construct their own ecofriendly homes. Here, the makers work with a more extended idea of time, one that correlates with a pronounced sensitivity to materials and ecology.

Considering these two cases together, we draw out an important analytical point: that the different situations or processes of making reveal different senses of the present, and, furthermore, that different processes of making may invoke or at least encourage different perceptions of time. We refer to this phenomenon as 'different presents in the making', whereby socialities of making, perceptions of time, involvements with materials and sensitivities to ecology become bound-up together and co-productive of one another. Underlying our point here is the idea that the grander notions of 'future', 'society' and 'ecology', and the possibilities that they entail, are always grounded in the experiential qualities of the present.

Whilst we are critical of the example of mainstream design we see in our first case, and largely supportive of the alternative presented in the latter, our point is not to set them in opposition to one another. Instead, the alternative approach of the latter opens up possibilities for practices of design and anthropology which are attuned to more extended dynamics of time, materials and ecology. Furthermore, we position ourselves within a stream of recent design anthropology thinking that considers 'ethnographies of the possible' (Halse 2013), adding our voices to attempts to "counter the simplified image of ethnographers documenting existing practices and designers inventing future practices' (ibid: 184). We concur with Otto and Smith when they suggest that a key contribution to be made by design anthropology is 'to extend the temporal horizon both forward and backward' (2013: 4). 
With others within this stream (Gunn et al 2013; Halse 2013; Otto 2013) we proceed in part by turning to the idea of the present and by drawing upon the argument that the present is "constitutive of both past and future' (Halse, paraphrasing George Herbert Mead, 2013: 184). In this vein, Joachim Halse suggests that 'that which is prototyped during a design event can be understood as extending the boundaries of the present' (ibid). Here, in this chapter, we draw upon our fieldwork to highlight practices of design and making that both depend upon and generate extended (that is, historically sensitive and future-oriented) senses of the present. These practices often seem to do this by offering-up for consideration critical-hopeful possible alternatives alternatives that are often beyond the boundaries of the present as it is currently conceived.

In drawing upon our fieldwork we intend to yield a fine-grained understanding of the everyday (in regular anthropological fashion), whilst pursuing a hope that 'the future could be different' (Bezaitis and Robinson 2011: 185), and it is here, in such a combination, that we think there lies a sense of what it means to practice design anthropology. That is to say that we pursue our work committed to a detailed elucidation of social life, but rather than being inclined to impress such insights into an ethnography of 'descriptive or documentary aims of which impose their own finalities' (Ingold 2014: 390), we alternatively wish to energise and empower anthropological insight in an active expository stance on design 'that could help us to think through its history and possibilities in a more critical and generative way' (Suchman 2011: 3). This would be a stance that extends the imaginative potential of anthropology to 'join in correspondence with those with whom we learn or among whom we study, in a movement that goes forward rather than back in time' (Ingold 2014: 390). Hence, it is with a purposeful, critical and exigent address that we carry a design anthropology not so much towards a disciplinary exchange of methods or innovation in research and design, but more towards a position from which it can combine a concern with critically interpreting the world with the intent to change it for the better (Marx 2014[1845]).

We also aim to further anthropological engagements with making beyond those with craft practices and towards a critical interest in 'professional technology design' (Suchman 2011: 1). However, while keenly following Suchman's critical perspective, we do not find our anthropological approach aligning with either of her binary positions of 'anthropology as (or for) design' (ibid) or 'anthropology of design' (ibid). That is, we are with Suchman when she is cautious about the idea of design 'as a model for anthropology's future' (ibid), but do not see the best alternative to this as being the adoption of an ' $o f$ ' stance that ultimately sees design 'best positioned as a problematic object for an anthropology of the contemporary' (ibid). For if anthropological engagement recourses to conventionally positioning design as an object of examination, then a significant opportunity to grasp the potentially enlightening collaborative future of design anthropology as an integrated field has been missed. Moreover, our fieldwork reveals that makers - whether in arts, crafts, design or technology - possess their own self-critical capacities, with many striving to work critically and ecologically in their practice. We would rather, then, join with these socially hopeful projects, and add our critical and constructive energies to the efforts of those designers and makers, who, like many people, attempt to find a course in life that contributes to social, political and ecological transformation.

Thus, working beyond Suchman's as and of binary, we tend towards Ingold's (2011: 226) anthropology with. Here we work with anthropology as a line of enquiry that can weave-in with the lives of others, rather than as a discipline which has to encounter a socially encapsulated other. This, we think, is a much more empowering and hopeful future orientation for anthropology and design than that offered by remaining in 
a relationship of 'critic' versus 'subject of criticism'. Of course, to carry out an anthropology that is genuinely with others involves its challenges. To do so, takes time, in part to gain the trust of participants, and much work to identify how one, as anthropologist, can be practically useful to projects that are in-the-making. When the skills possessed by an anthropologist are less valuable to projects at hand, they can often end-up more on the sidelines of making activity and thus find themselves acquiring more of an of position. ${ }^{1}$ In our experience, being able to become closely involved in a with capacity involves the shared unfolding of a subtle, careful and developmental course of discovering how one's own personal and anthropological skills can best be brought to bear on the particular characteristics of a common project. By steering and following this course, we have found that the anthropologist can lend a particularly valuable contribution by encouraging makers to attend to the deeper complexities of their practice and helping to realise the unfolding of new possibilities - possibilities which might have otherwise gone unnoticed. Overall, however, our trajectory towards a design anthropology with exists as one of ongoing aspiration and work-in-progress.

\section{Making in a close-present}

Our first field case is concerned with everyday working life in a commercial product design studio located on an industrial estate adjacent to the centre of a large UK city. Here, through 2012 to 2013, Anusas engaged in participant observation for a period of eight months: working as a full-time product designer, assisting project planning, research, conceptual design and prototype making, within a team of approximately eight people. We draw on this case because it is representative of design studios that operate within an industrial context and carry out a diversity of projects with specific creative and technical requirements. This particular studio designs products for professional, consumer, medical and energy sectors, and typically has numerous projects running in parallel with different demands on expertise and time. Its capacities of making are diverse in terms of the range of skills employed and the associated tools and materials used, and on any day it is typical to see the practitioners engaged with freehand drawing, computer modelling, calculations and prototype-making using manual and machine skills.

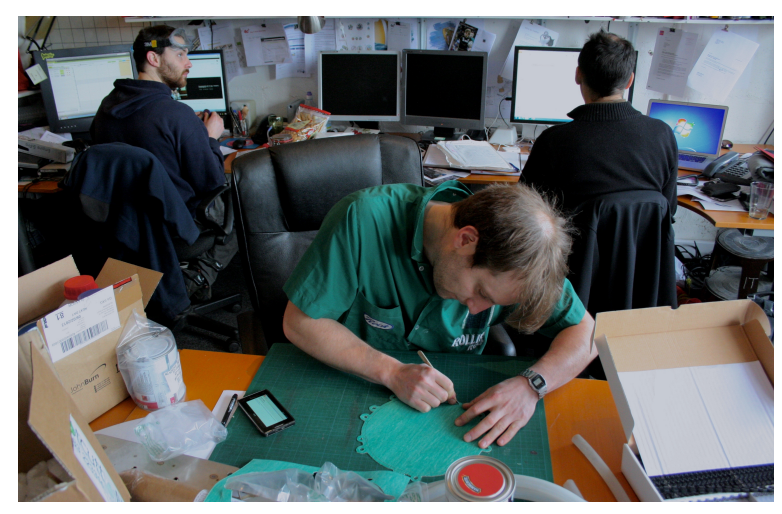

Figure 1: A typical working environment of a UK product design studio. In this case the practitioners are concurrently engaged in conversation, computation and making. Photograph: Mike Anusas. 
Observations within the studio revealed time experienced as a linear particularization, where positioned intervals of minutes, hours, days and weeks are used to express temporal positions and outlooks within projects. Rarely do concerns with time extend beyond the largest of these intervals, and while sometimes there is reflection upon the past, there is overwhelmingly an orientation towards a future, as part of a plan of action. This notion of time is thus concerned with instances of time as detailed entities which are about to occur or will soon occur, and as particular, positioned entities they emphatically bind social activity into temporal units associated with specific actions. We refer to this notion of time as a close-present, and it is this temporal formation of the present that we observed as underpinning and informing many of the qualities and possibilities of design and making in the studio.

Time as a close-present is evident in much of the verbal, bodily and material sociality of a commercial product design studio. It is integral and definitive in the emergence of projects and actively structures what might be done, when and by whom. Specific time intervals are continually discussed as practitioners coordinate their work with their peers and communicate what they or others might achieve 'this morning', 'later tomorrow' or the 'by the middle of next week'. The close-present is therefore sustained as a force of both pressure and tension, with a regularity of verbal expressions concerning how time is in short supply and not felt to be under the practitioners control. To give an example, at the outset of a project two practitioners expressed a sense of this temporal tautness and compression in relation to their work:

Practitioner 1: "Yeah, well, as soon as we picked it up, it was, "Right, the timescale is really tight on this." And then it -we've been - we seem to have been working harder."

Practitioner 2: "The pace of this project ... we're under a lot of pressure to deliver in a very short space of time." Informal and formal reviews of projects also regularly involve bodily expressions of time, most typically gestured through a broadening of the arms denoting the stretch of a linear spectrum over hours, days or weeks. Furthermore, the studio commonly features material expressions of time in sketch-books and wall drawings as future-projected timelines, annotated with intervals, actions and plans:

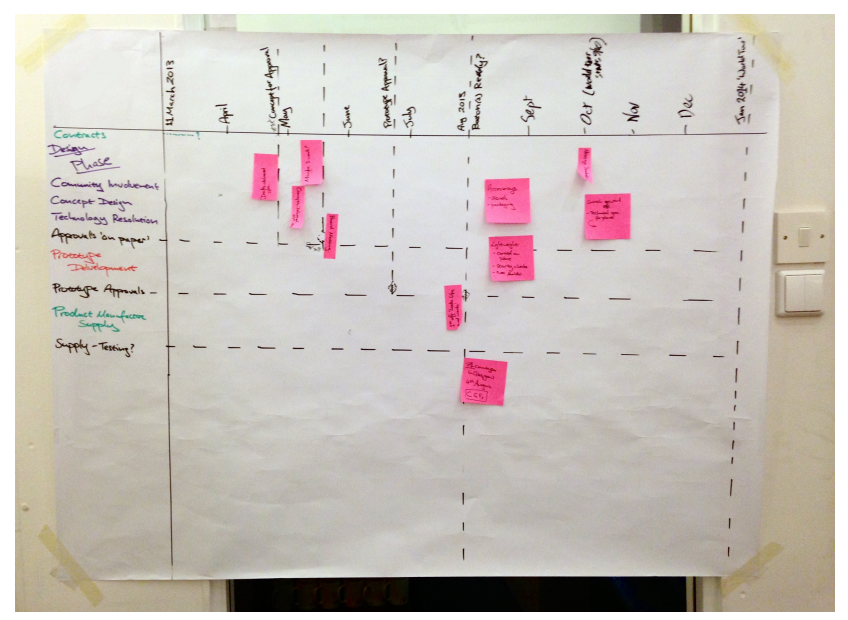

Figure 2: Project timeline drawing showing linear left-to-right progression of time and tasks across months.

Photograph: Mike Anusas. 
For these designers, specific notions of time underpin the very character of their practice and the fundamental conceptual nature of the things they make. This characteristic of work evolves throughout their education, where they learn about design in reference to geometric diagrams that depict design as a unidirectional, step-by-step process, moving from left to right through diverging and converging patterns of activity (Figure 3). Such diagrams, exemplified by Ulrich and Eppinger's (2012: 14) 'generic product development process' and the UK Design Council's (2015) 'Double Diamond', have become pronounced points of reference within product design education and practice.

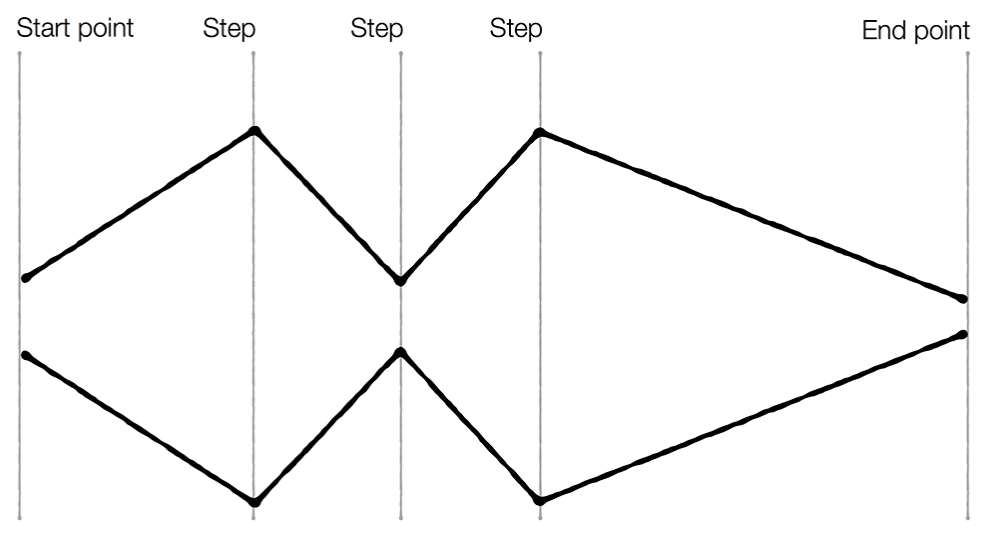

Figure 3: Product design process diagrams typically look like the one above: an arrangement of straight lines, positioned relative to one another and read in a left to right progression. The angular arrangement denotes converging and diverging patterns of work, set out in steps along a temporal movement.

These types of diagrams communicate making as a process activated out of an arbitrary free point, which then works in procession towards a neatly concluded point of production: no prior social or material history is indicated, nor are any loose ends of further (i.e. post-production) material-becoming or controversy over where the product might go or do. Moreover, such diagrams are time neutral, existing more as templates to be transposed onto a development time associated with specific product categories. Within the studio observed, this typically implied a few working days for packaging design, a few weeks or months for consumer product design, or multiples of years for industrial systems design. These development times correlate directly with another timescale: the length of time that the artefact or system is expected to be operational within its social setting, that is, the 'product life span'. As soon as a new project is introduced to the studio, its alignment to a particular category of product carries with it an assumption regarding its life span. Thus, the very genesis of any project inherently involves specific particularisations of time. For example: for packaging, product life span is assumed as seconds, minutes, days or weeks; for consumer products, months or years; and for industrial systems, multiples of years.

Assumptions concerning development times impose expectations and pressures on the design practitioners, and such temporal pressure is compounded by the specific demands of project clients, as well as the aspirations of the practitioners themselves. Clients are keen to see development times lessened to decrease 'time to market' and lever competitive advantage. As a result, practitioners often preoccupy themselves with how quickly and effectively they can achieve results, and by doing so they follow a shared perspective that a 
faster design process is a more advanced one. Furthermore, the studio will typically be keen to move through projects as quickly as possible, getting them 'off the books' in order to channel through further business and sustain their livelihood. These factors mean that the designers work with a high level of concentration on specific creative and technical tasks, and thus they give the impression that a characteristic of good design practice is being 'head down' and focused on a 'task at hand'. It is in this state that the practitioners often seem most comfortable and happy.

Importantly, these forces of time also shape the character of the tools and materials that the designers work with. All manner of paper, pens, substances, components, hand-tools, machinery and computational systems that the practitioners are immersed in, have technically evolved not just for their enhanced creativity and technical mastery but also because they are temporally expedient. Materials within the studio rarely appear in anything resembling a 'raw' state, but more often than not as volumes in cylindrical or block form, so as to be quickly able to be bent, shaped or cut towards the intention of a concept design. Computational work, such as that concerned with Computer-Aided Design (CAD) similarly relies predominantly on the use of preprogrammed geometric volumes that can be rapidly modified and assembled to create design propositions. Freehand drawing, meanwhile, is typically carried out on basic office paper or dry-wipe white-boards, thus giving drawings an ephemeral quality, carrying their purpose more as a means to an end. However, this intrinsic tie between an ever-intensifying close-present guiding the course of material formation, is perhaps best exemplified by the practitioners preoccupation with technical developments in '3D printing': a method of fabricating physical parts with information drawn directly from CAD data that is categorised by the UK manufacturing industry as a leading 'time compression technology'.2

\section{Making alternatives in a far-reaching-present}

Our second context of making is that observed and participated in by Harkness as she lived and worked as an anthropologist and a volunteer builder for over a year with people building environmentally-friendly homes for themselves and their communities. Drawing upon this research with the builders of off-grid eco-homes, called Earthships, in both Scotland and New Mexico, we can posit that the design and making of these homes displays (and is product of) a different sense of the present to that which we saw in the design studio. It is a present that is neither close nor limited (a close-present), but one that, as Harkness (2009) has suggested, extends its reach far out into the world, both geographically and temporally.

Earthships are built with recycled and what the builders call 'natural' materials; they use renewable resources for their power; they catch their own rainwater and have their own off-grid plant-based filtration systems for their dirty water. Their forms follow these factors and functions. Importantly, although Earthships provide their dwellers with all the comforts and conveniences of a modern home, they are designed and built in a way that is participatory, ecological and often quite different from modes of housing construction that are conventional, professionalised and mass-produced. In the Earthship builders' forging of dwellings and new ways of living we see impulses towards creating alternative futures, impulses similar to that which Bezaitis and Robinson have described as 'the idea that the future could be different' (2011: 185, emphasis in original). This is an impulse that signals of 'the potential to bring change to the world, to shift the ground, to alter the rules' (ibid). Those that build Earthships are literally and metaphorically bringing change to the world and constituting 
a 'shifting of the ground' - albeit through relatively small alternative movements - in the field and practices of architecture and design. For Earthships are an architectural phenomenon of the so-called West, and yet they are the embodiment of a critique of this same system: they present a challenge to its hegemony via the provision or demonstration of an alternative to it (Harkness 2009). The builder-dwellers of Earthships are situated within a far-reaching and open present, a present in which there is a sense of now that extends towards and connects times, places, peoples, and one which is burgeoning with the possibility of difference whilst being aware of what has come before.

The Earthship's alterity is connected to the builder-dweller's senses of time and materiality. Earthships are built by their owner-dwellers and by volunteer labour from friends, family and others that want to learn how to build. They are built by low-tech, labour-intensive means from the excavated earth of the site itself and from salvaged materials considered 'waste' or 'trash' by society, such as used tyres and bottles. ${ }^{3}$

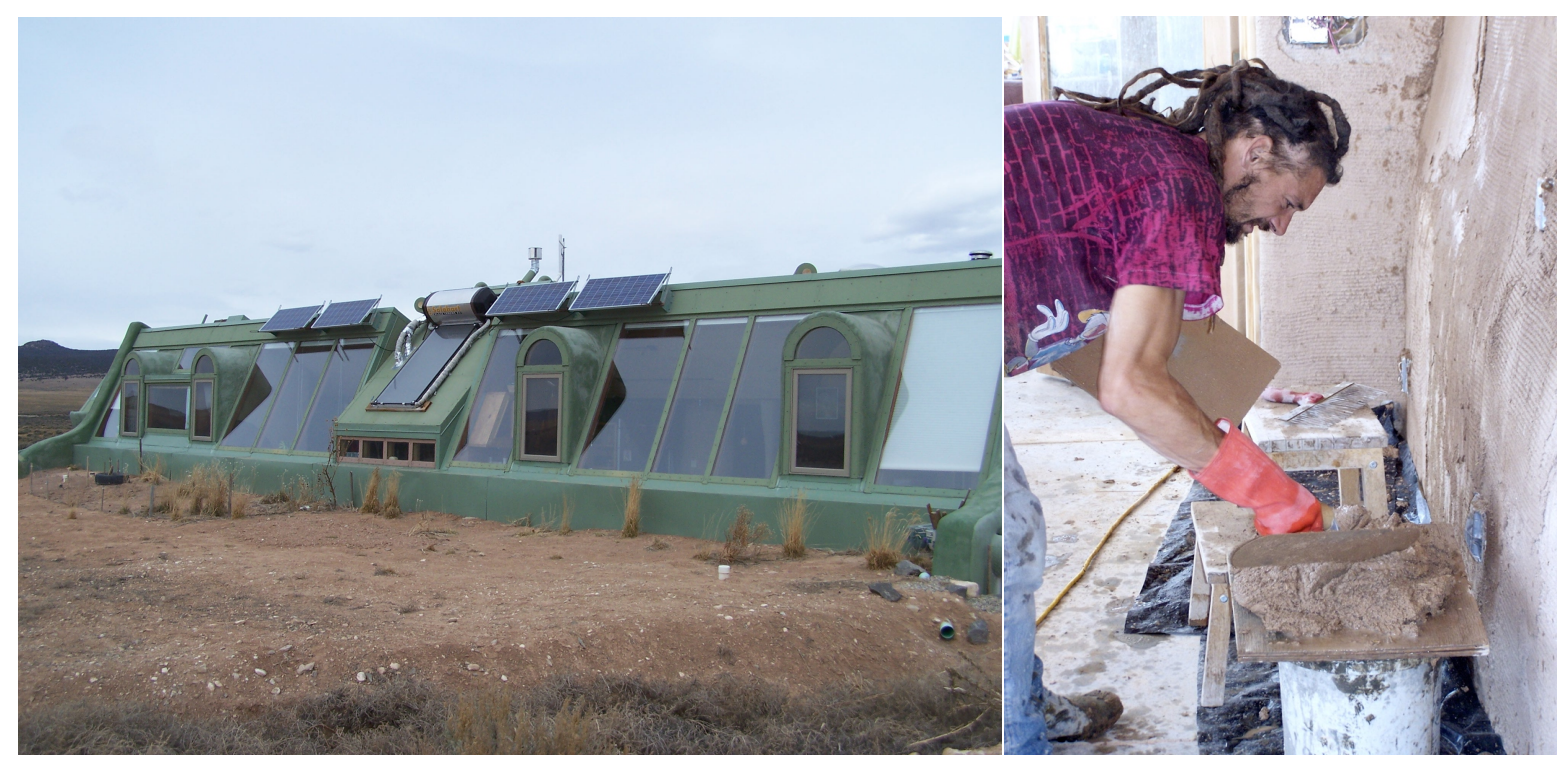

Figure 4: Left: The south face of a relatively newly built Earthship home, New Mexico, 2006. The north face, not visible here, is 'bermed', or banked-up, with earth from the site. Right: An Earthship builder 'mudding' a wall with adobe (earthen) plaster. Photographs: Rachel Harkness.

Thus, within Earthship-building circles, people (some paid in cash, some in kind or in food, and some not paid at all because of other reciprocal ties with the dweller) construct homes for each other from materials that have been removed from a conventional linear scheme of turning extracted raw material to waste. That is a scheme that sees material turned into product, then that product used and cast off, only to then see it be moved into a final phase of stasis, landfill or death. In Earthships these materials (car tyres, aluminium cans, glass bottles, pieces of architectural salvage) are renewed and repurposed and they carry on. The Earthship-builders use earth and other 'natural' materials such as sheep's wool insulation too, and these are used as if they are 'borrowed' by the builders from their wider environments: they are incorporated with the knowledge that they will cycle back into the wider environment without negative or gross impact upon it.

The building of Earthships happens in 'free' time of evenings, weekends and holidays, and during the more conventional 'work' times of $9 \mathrm{am}-5 \mathrm{pm}$. Boundaries between work and play, between the private space of 
the home and public spaces of work or meeting, are thus blurred. The way that Earthship-dwellers build and live is not so strictly clock-bound as their on-grid neighbours; schedules of building lurch and race depending on the people at the building's core and their lives, and upon the light and temperature afforded by season and weather. Furthermore, because many of the materials used to build Earthships are free or of low cost, and because lowtech methods and one's own labour are central to the Earthship concept, once the builder has secured land they are generally able to reduce their participation in conventional wage labour for money. Earthship homes are also powered by renewable energy systems (cheap to run once installed) and supplied by water catchment and treatment systems that tend to mimic the weather cycles much greater than them that they tap into. This tends to mean that as the sun rises, shines and sets, the rain falls or the snow melts, as the wind blows or dies down, and as the plants (of the dirty-water filtration system) grow, the builders and their buildings are part of these cyclical occurrences. Resultantly, their sense of time, like the shifting of their dependencies, tends to shift into those of their renewable resources, their water systems and their gardens.

Crucially, the eco-builders of Earthships (as is common with people across the wider field of ecodesign and making) make the far-reaching present real or manifest in the materials that they use and the way they make things because of a shared environmental sensibility or awareness. Environmental sensibilities and awareness then also become embedded in the everyday material culture of Earthships. For example, the figure below shows how something as simple a light switch is visually formed so that it can be apprehended not just as a discreet entity in and of itself, but also as a point of relation between the utility of light and wider solar ecologies.

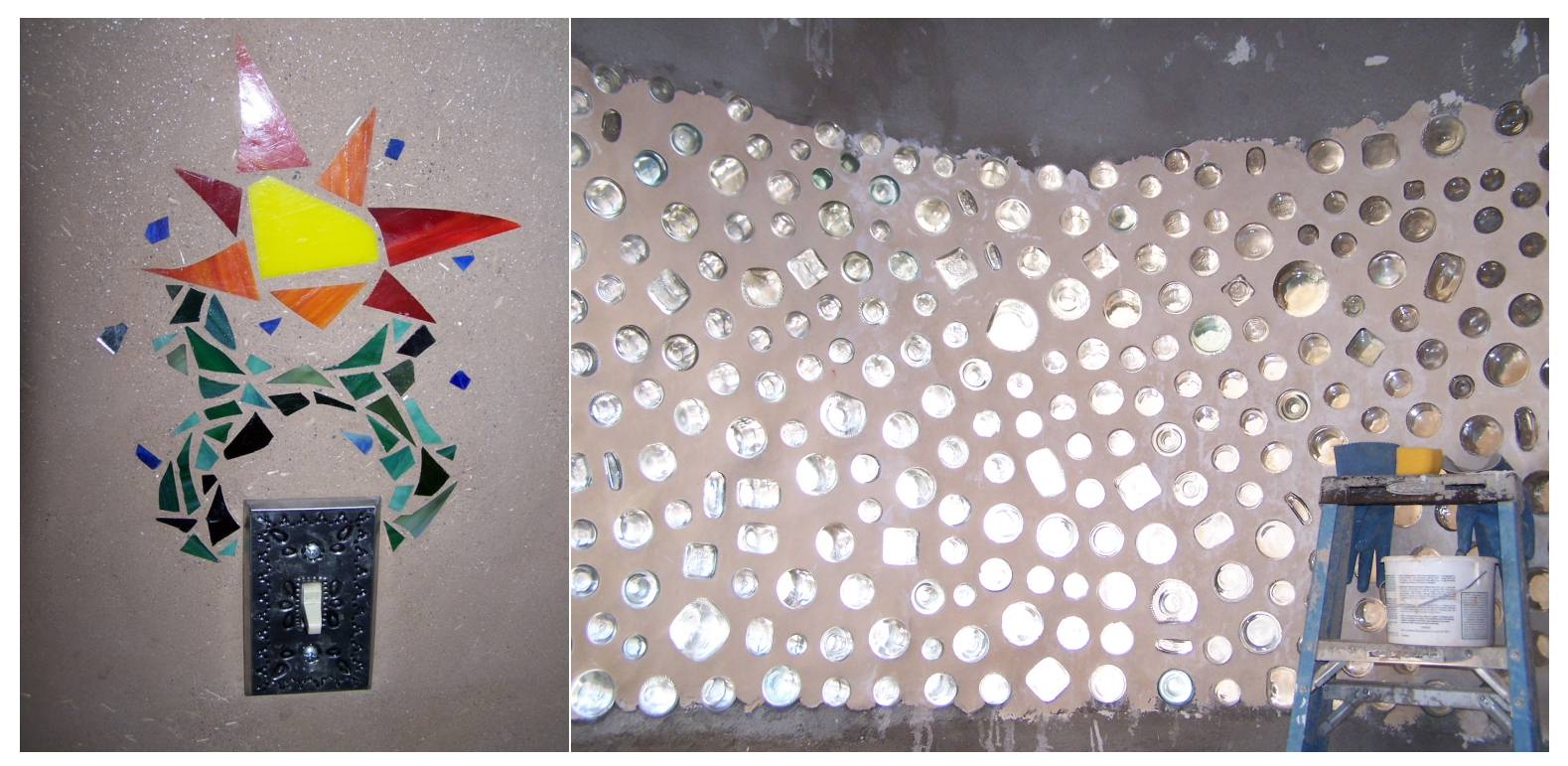

Figure 5: Images from Earthship homes in New Mexico, United States. Left: Mosaic elaboration of a light switch in an earthen-plaster and rammed-earth-tyre wall. Right: A curved glass bottle-brick bathroom wall inthe-making. Photographs: Rachel Harkness.

Though not everyone holds this sensibility in the same way, or even to the same extent, it will tend to include an agreement that many of the ways that people live on the planet are destructive. The wealthy people of the energy-intensive mass-consumerist so-called developed countries in the West are seen to have perhaps the most 
damaging ways of living. These ways are destructive not only to the natural environment of plants, animals, air, soil and water around them, but also to other people and ultimately also to their own health and happiness too. Earthship-builders gain their education in eco-building in various ways. Sometimes they have gleaned it themselves from 'how-to' eco-build books and socio-environmental literature such as Leopold's Sand County Almanac (1949) or Rachel Carson's Silent Spring (1965). Other times it will have been picked-up from fellow builders as they volunteered or worked together on eco-builds, or sometimes they will have had more formal environmental or ecological schooling. Often their education is by a mix of all of these means. Whichever way they have learnt, they talk about pollution - the phenomenon that their re-use of rubbish helps to combat - as a temporally-extended phenomenon. They are both cognizant and vocal about the fact that pollution lasts, often long after the polluters, and its impact (whether plastic in the sea or chemical pollution and atmospheric change) reaches further than its initial area of release. The majority of these people have learnt and taken to heart that what is done or made here and now can have long-lasting and far-reaching impact, good or bad! Therefore, they take the time to source materials in relation to their provenance and potential future use; they are conscious of the limited resources on our planet; they consider architectural components not just in terms of their formative qualities, but also in terms of their embodied energy and/or their carbon footprint. This all takes time and care often much more time than if they just used the resources supplied by their local building suppliers. Recycling, re-using, reclaiming and repurposing are integral to the activities of building and lend a cyclical sensibility to the whole project, where even human excretes are re-envisioned as useful and plentiful resources.

The eco-builders of Earthships often express themselves to be 'empowered' to forge alternative futures through being equipped to critique histories and the status quo. They draw on ideas of living from other places and times as design influences and thus, are able to imagine, and literally build, different ways of living. Thus, whether it is in referencing the communal efforts involved in American barn-raising as a historical precedent for the way that the Earthship community help each other to build, or the particular influence that, say, a style of North African vernacular architecture had on the way that they designed and constructed the adobe (earth) details of their own individual desert home, Earthship builders gather their influences from far and wide just as they see themselves as situated within the wider world, not only their immediate locale. Furthermore, as the Earthship owner-dweller builds their own home (though not necessarily, or even commonly, on their own), the building competence that they possess and the relative freedom they have to experiment with their own building, on their own land, allows them to create homes which are intentionally understood as on-going, open to change and adaptation. Homes are rarely finished here it seems, with additions and adaptations and ongoing, in-progress-whilst-living-in building, often being the norm. These buildings are transformative projects, coupling action at the everyday level of the home with a social, environmental and global perspective, connecting the everyday moment with other times (past and future, both).

\section{The Possibilities Afforded by Embracing the Extended Dynamics of Time, Materials and Ecology}

Both cases of making that we draw upon are (as with all practices of making) ecologically situated: taking place within a dynamic of materials, organisms and forces. However, the way in which a consciousness of ecology is present within each case is notably different, and this correlates with different relations with materials and time. 
We now elaborate on this link between the different sorts of present being experienced and the quality of people's material, social and ecological engagements.

In the first case of the design studio, the practitioners' growth of their ecological awareness is not the primary intention of their practice. Rather, they are subject to, or complicit in, an industry that is primarily concerned with the formation of material objects and with the aim of enhancing human social and technical capacities whilst generating economic growth. However, in moments of reflection outwith the immersion of work towards a deadline, these practitioners do often express ecological concerns. ${ }^{4}$ Such concerns, when pursued, typically involve engagements with reading on the subject ${ }^{5}$, or interest in state eco-initiatives such as those concerning the development of "circular economies" ${ }^{\prime 6}$. These inclinations signal an openness to the social and cultural aspects of ecology as well as an interest in rethinking the fundamental conventions of design process and the material structures of manufacturing economies. However, the extent to which these design studio practitioners can act upon ecological concerns is always subservient to the interests of the project and the client. As we have seen, working within a close-present affords little opportunity for deeper reflection concerning the origin or the future of the materials they work with. Despite the existence of ecological design thinking - such as Stewart Brand's notion of the 'long now' (2000) which pushes to make long-term thinking more common - there still seems to be little momentum towards a perspective in product design which might offer a more radical and temporally-mobile sense of the present. That is, much 'ecological' product design fits too easily into the conventional ontologies the designers have acquired through their standard routes of learning. Ecological design is therefore often presented as another add-on methodology to product design, subsumed into a temporally-contracted close-present commercial perspective.

In our second case, the eco-builders are building their own homes, over time and in a different type of present that is far-reaching in its outlook. These eco-builder practitioners are seemingly very aware - in their own way - that 'matter matters' (Barad 2003). They choose materials carefully and place great value upon hands-on engagement with them, while in-the-making. They hold the materiality of their physical surroundings as being incredibly important to their own health and wellbeing and that of others (human and non-human both). In addition to a different model of labour and ownership of the means of production, the approach to making that the self-builders take is fundamentally not object-bound. Their approach is generally an anti-consumerist one that is at play with multiple and simultaneous material, spatial, political, ecological and temporal concerns in the midst of a fluid materiality. Here the builder works with these flows to remain sensitive to their Earthship dwelling and its relationship with nearby people and habitats, as well as with global-scale transformations and atmospheres. Though building 'off-grid' so-to-speak, these builders are the opposite of isolationist: they are celebrators of life's interdependences and flows. Furthermore, working with them as a researcher, one cannot help but become aware of and responsive to these characteristics of life, living and making.

On the subject of materials Karen Barad has suggested that '...materiality is an active factor in processes of materialization. Nature is neither a passive surface awaiting the mark of culture nor the end product of cultural performances' (Barad 2003: 827). With thinkers such as Ingold (2012), who paints a picture of the world as a dynamic meshwork, and DeLanda (1997), who has argued for a deeply material and non-linear understanding of time, Barad therefore cogently presents the idea that 'matter is not a fixed essence; rather, matter is substance in its intra-active becoming — not a thing but a doing' (2003: 828). These ideas are highly evocative of the Earthship-builders approach to living and dwelling: they and their makings become together in 
a world in motion. Their homes materialize as part of the builders' movement within the world's fluxes over time and from place to place. Thus, to work with Earthship builders is to feel these contemporary anthropological ideas become vital, to be able to think through, and think-through-making, this interpretation in a lived reality.

To summarise, the different presents that we have encountered in our research are indicative and generative of different socio-material ecological relationships with/in the world. In the nascent interest in circular design economies or the more radical eco-self-build movements, what is key is the forging of a different, alternative path. In fact, it is the myriad forging of many alternatives. It is this spirit of possible alternatives, of acting in a socially- and ecologically-conscious way, and of critical material engagement as a designer-maker in/of the world, that we then consider as being the sphere for our own practice as design anthropologists. We are inspired to think that our practice, here at this design/anthropology intersection (Bezaitis and Robinson 2011: 185), could be similarly oriented towards hopeful, socially-aware and ecological transformation, that we too could extend our present, and reach, with others, for different material and more ecological futures.

So, we close with a proposition: that there be a move towards a hopeful, open and projective ecological design anthropology practice. We believe that the adoption of a far-reaching present in processes of design, analysis and making can usefully dislodge both linear ideas of progress and object-bound and temporallylimited conceptions of materiality. It can pave the way for an acknowledgement of the unbounded and energetic qualities of materials, and reveal an extended sense of temporality where materials are in flux, continually undergoing transformation. We see an opportunity here for widespread hopeful design throughout communities and societies and a design anthropology that has far-reaching and long-term thinking at its core. This would be a design anthropology that draws on a reflexive and diverse understanding of life's multiple-temporalities, and that directs such insight towards the formulation of a more open, socially-just and environmentally-conscious material life, intent on continued reinterpretation and resisting foreclosure.

\section{Acknowledgements}

We would like to acknowledge the support of the European Research Council funded 'Knowing From the Inside' project (University of Aberdeen) and the Danish Research Network for Design Anthropology. We would also like to thank the editors, Ton Otto and Rachel Charlotte Smith, and our network colleagues, Adam Drazin and Ramia Mazé, for their peer reviewing and input.

\section{References}

Barad, K. (2003), "Posthumanist Performativity: Toward an Understanding of How Matter Comes to Matter", Signs: Journal of Women in Culture and Society, 28(3): 801-831.

Bezaitis, M. and Robinson, R. (2011), "Valuable to Values: How 'User Research' Ought to Change,” in A. Clarke (ed.), Design Anthropology: Object Culture in the 21st Century, New York: Springer Wien, 184-201. 
Brand, S. (2000), The Clock of the Long Now: Time and Responsibility: The Ideas Behind the World's Slowest Computer, New York, NY: Basic Books.

Carson, R. (1965), Silent Spring. Harmondsworth: Penguin, in association with Hamilton.

Chapman, J. (2005), Emotionally Durable Design: Objects, Experiences and Empathy, London: Earthscan.

De Landa, M. (1997), A Thousand Years of Nonlinear History. Brooklyn, NY: Zone Books.

Design Council (2015), What is the Double Diamond? Available at: http://www.designcouncil.org.uk/newsopinion/design-process-what-double-diamond. Accessed September 16, 2015.

Gunn, W., Otto, T. and Smith, R. C. (eds.) (2013), Design Anthropology: Theory and Practice. London: Bloomsbury.

Halse, J. (2013), "Ethnographies of the Possible”, in Gunn, W., Otto, T. and Smith, R. C. (eds.), Design Anthropology: Theory and Practice, London: Bloomsbury, 180-196.

Harkness, R. (2009), Thinking Building Dwelling: Examining Earthships in Taos, New Mexico and Fife, Scotland. Unpublished Thesis. University of Aberdeen.

Harvey, D. (2000), Spaces of Hope. Edinburgh: Edinburgh University Press.

Ingold, T. (2011), Being Alive: Essays on Movement, Knowledge and Description. Abingdon: Routledge.

Ingold, T. (2012), “Toward an Ecology of Materials”, Annual Review of Anthropology, 41(4): 27-42.

Ingold, T. (2014), “That's Enough About Ethnography!”, HAU: Journal of Ethnographic Theory, 4(1): 383395 .

Leopold, A. (1949), A Sand County Almanac and Sketches Here and There. New York, NY: Oxford University Press.

Marx, K. [1845], “Theses on Feuerbach” reproduced on The Marx/Engels Internet Archive, www.marxists.org/archive/marx/works/1845/theses/engels.htm [Accessed 20 August 2014.]

Mazé, R. (2007), Occupying Time: Design, technology, and the form of interaction. (PhD thesis) Stockholm: Axl Books.

McDonough, W. and Braungart, M. (2002), Cradle to Cradle: Remaking the Way We Make Things. New York: North Point Press.

Miyazaki, H. (2004), The Method of Hope: Anthropology, Philosophy and Fijian Knowledge. Redwood City, CA: Stanford University Press.

Otto, T. (2013), “Times of the Other: The Temporalities of Ethnographic Fieldwork”, Social Analysis, 57(1): 64-79.

Otto, T. and Smith, R. C. (2013), “Design Anthropology: A Distinct Style of Knowing”, in Gunn, W., Otto, T. and Smith, R. C. (eds.), Design Anthropology: Theory and Practice. London: Bloomsbury, 1-29.

Shove, E., Watson, M., Hand, M. and Ingram, J. (2007), The Design of Everyday Life. Oxford: Berg. 
Suchman, L. (2011), “Anthropological Relocations and the Limits of Design”, Annual Review of Anthropology, 40: $1-18$.

Ulrich, K. T. and Eppinger, S. D. (2012), Product Design and Development. New York, NY: McGraw-Hill.

Zournazi, M. (2003), Hope: New Philosophies for Change. New York, NY: Routledge.

${ }^{1}$ Of course, this is valuable in and of itself in that it affords opportunity to reflect upon things from a different angle.

${ }^{2}$ The use of this phrase to denote technology as an agent for reducing development time is reflected in its acronymisation in the title of a leading UK technology trade show: 'TCT Show + Personalize' run by the Rapid News Communications Group.

${ }^{3}$ Materials that - we might note - take time to collect and gather.

${ }^{4}$ The level of this concern tended to vary between individuals: some would regard an ecological focus as a progression of design thinking and methodology; others would hold ecological concerns close to their hearts, speaking of strong ethical orientations and even personal dilemmas about the effect of their own professional work.

${ }^{5}$ The practitioners here showed interest in McDonough and Braungart's (2002) case for industry to adopt a cyclical, rather than unidirectional, design and manufacturing process, and an enthusiasm for the way in which Chapman (2005) foregrounds issues of emotional material attachment in ecological design.

${ }^{6}$ The conceptual framework of the 'Circular Economy' highlights the transformational properties and potential of materials through considering artefacts as 'roundputs', designed to be 'made and made again' as part of processes of continual cyclical production and material flow. Such frameworks, which essentially highlight that materials have both histories and futures, sit in notable contrast to conventional linear depictions of the design process where materials appear to arrive from a virgin, neutral origin and, after a life as a specific object or artefact, appear to have no future destination as they disappear into the hidden realms of 'waste'. 